\title{
Associations of changes in patient characteristics and management with decrease in mortality rates of men and women with ST-elevation myocardial infarction - a propensity score-matched analysis
}

\author{
Lukasz Zandecki ${ }^{1,2}$, Marianna Janion ${ }^{1,2}$, Marcin Sadowski ${ }^{2,3}$, Jacek Kurzawski ${ }^{1}$, Lech Polonski ${ }^{4}$, \\ Marek Gierlotka ${ }^{4}$, Mariusz Gasior ${ }^{4}$
}

\author{
${ }^{1} 2^{\text {nd }}$ Cardiology Clinic, Swietokrzyskie Cardiology Center, Kielce, Poland \\ ${ }^{2}$ The Faculty of Medicine and Health Sciences, Jan Kochanowski University, Kielce, \\ Poland \\ ${ }^{3}$ Department of Interventional Cardiology, Swietokrzyskie Cardiology Center, Kielce, \\ Poland \\ ${ }^{4} 3^{\text {rd }}$ Department of Cardiology, School of Medicine with the Division of Dentistry \\ in Zabrze, Medical University of Silesia in Katowice, Silesian Centre for Heart \\ Diseases, Zabrze, Poland
}

Submitted: 16 October 2017

Accepted: 15 November 2017

Arch Med Sci 2020; 16 (4): 772-780

DOI: https://doi.org/10.5114/aoms.2020.93458

Copyright () 2020 Termedia \& Banach

\section{Abstract}

Introduction: The aim of this study is to estimate how much of the recent decrease in mortality among patients with myocardial infarction with ST-segment elevation (STEMI) can be attributed to improved treatment strategies, and how much it is related to changes in baseline clinical characteristics, and to compare these findings for men and women.

Material and methods: This was a retrospective analysis of 32,790 patients with STEMI from the Polish Registry of Acute Coronary Syndromes PL-ACS hospitalised in 2005 and 2011. Changes in treatment strategies including pharmacotherapy were analysed. Observed in-hospital and 12-month mortality rates were compared with the outcomes in the groups matched on the propensity scores.

Results: There was a substantial improvement in STEMI patient management between 2005 and 2011 in Poland. It included greater use of percutaneous coronary interventions and other guideline-based adjunctive therapies, and it was associated with a significant decline in in-hospital mortality. Relative 12-month mortality reduction rates were less pronounced and more related to changes in patients' clinical characteristics. Higher mortality risk reductions were observed in women and were driven by relatively more positive changes in their baseline risk profiles when compared to men.

Conclusions: The progress in the treatment strategies has helped to achieve better survival rates in STEMI patients. However, the ongoing changes in clinical characteristics of patients also played an important role, especially in women. Clinicians should focus on modifiable risk factors and post-discharge management to possibly prolong the positive aspects of in-hospital efforts.

Key words: women, registry, all-cause mortality, in-hospital mortality, ST-elevation myocardial infarction, propensity score, clinical characteristics, gender-related matters, management and treatment.

\author{
Corresponding author: \\ Lukasz Zandecki \\ $2^{\text {nd }}$ Cardiology Clinic \\ Swietokrzyskie Cardiology \\ Center \\ 45 Grunwaldzka St \\ 25-736 Kielce, Poland \\ E-mail: \\ lukasz.zandecki@gmail.com
}




\section{Introduction}

The management of myocardial infarction with ST-segment elevation (STEMI) has undergone major changes in recent decades. Although many recent studies have confirmed a reduction of crude mortality rates in STEMI patients [1-5], there is some uncertainty about the determinants of this decline. In fact, studies investigating reasons for the mortality decline in STEMI are limited $[4,6,7]$. Early reperfusion is the most important predictor of favourable outcome in STEMI patients, with primary percutaneous coronary intervention $(\mathrm{PCl})$ being the preferred strategy [8]. The widespread use of $\mathrm{PCl}$, the implementation of recent advances in angioplasty devices, and pharmacologic therapy have unquestionably contributed to better acute survival rates as well as long-term prognosis in STEMI patients [9]. In view of the results of randomised, controlled trials in STEMI, it is often presumed that new treatments should be the main reason for mortality reduction. Although there is no doubt that changes in patient management are among the most important aspects related to decreased mortality in STEMI, the outcomes are also influenced by patients' risk profiles at presentation. It is known that STEMI patients' clinical characteristics at admission have markedly changed over the last decades and should be considered as an important prognostic factor to control for when analysing reasons for survival improvement [5].

In Poland, between 2005 and 2011 we witnessed significant progress in the interventional approach to STEMI treatment, which made Poland a model example of rapid progress in STEMI management, achieving one of the highest levels of utilisation of primary $\mathrm{PCl}$ in Europe [10]. In 2005 in Poland around half of all STEMI patients were treated with $\mathrm{PCl}$. Due to the rapidly increasing number of catheterisation labs this number rose to over $90 \%$ in 2011 [5, 11]. Concurrently, a significant decline in crude mortality rates among STEMI patients in Poland has also been observed [5, 12]. It is possible that other European counties could experience similar progress because large variations in reperfusion treatment are still present across Europe [10]. This is why we believe it is important to analyse and present details and outcomes of this evolvement [13].

In this population-based study we aim to estimate how much of the observed decrease in in-hospital and 12-month mortality in STEMI patients could be attributed to improved treatment strategies, and how much it was related to changes in baseline clinical characteristics, and compare these findings for men and women.

\section{Material and methods}

We analysed data on 32,790 patients with STEMI from the Polish Registry of Acute Coronary Syndromes PL-ACS. The patients were admitted to hospitals in Poland in 2005 (12,180 men and 6422 women) and in 2011 (9141 men, 5047 women). All patients registered in the PL-ACS registry in 2005 or 2011 with a confirmed diagnosis of STEMI were included in the current study. For the patients who presented more than once during the study period, only the first hospitalisation was analysed. The methodology of the PL-ACS Registry was described previously [14]. In brief, the PL-ACS Registry is an ongoing, nationwide, multicentre, prospective, observational study of consecutively hospitalised patients, representing the entire acute coronary syndrome (ACS) spectrum. The registry is a joint initiative of the Silesian Centre for Heart Diseases and the Polish Ministry of Health. All admitted patients with suspected ACS were screened for their eligibility to enter the registry, but they were not enrolled until ACS was confirmed. STEMI was defined as the presence of ST-segment elevation of $\geq 2 \mathrm{~mm}$ in the contiguous chest leads and/or ST-segment elevation of $\geq 1 \mathrm{~mm}$ in two or more standard leads or new left bundle branch block, together with positive cardiac necrosis markers. All-cause mortality data were obtained from the official mortality records of the National Health Fund. Study endpoints were in-hospital, and 12-month all-cause death. The vital statuses at discharge and after 12 months were available for all of the included patients.

In order to reduce the bias of confounding when using observational data to estimate effects of changes in treatment on STEMI patients' outcomes, a propensity score (PS) matching technique was applied. Methods based on PS were proposed in the early 1980 s by Rosenbaum and Rubin [15] and were dedicated to estimate causal relationships based on large non-randomised datasets. Recently, there has been increasing interest in these methods, and they have been developed and widely used also in medical and cardiological research [16].

All available baseline characteristics were incorporated into a regression model to estimate a PS for each individual. The overlap and the region of common support between the groups were checked by a visual inspection of the density distribution of the propensity scores in the 2005 and 2011 groups. Patients from 2005 and 2011 were matched one-to-one on their PS to samesex individuals within a pre-defined PS limit of $60 \%$ of standard error. Greedy nearest neighbour matching algorithm without replacement was used. Out of a total of 32,790 patients 14,160 men (7080 from 2005 and 7080 from 2011) and 
Table I. Balance of initial clinical characteristics covariates after propensity score matching

\begin{tabular}{|c|c|c|c|c|c|c|}
\hline \multirow[t]{2}{*}{ Factor } & \multicolumn{3}{|c|}{ Women } & \multicolumn{3}{|c|}{ Men } \\
\hline & $\begin{array}{c}2005 \\
n=3950\end{array}$ & $\begin{array}{c}2011 \\
n=3950\end{array}$ & S. diff. & $\begin{array}{c}2005 \\
n=7080\end{array}$ & $\begin{array}{c}2011 \\
n=7080\end{array}$ & S. diff. \\
\hline Age [years] & $69.2 \pm 11.9$ & $69.7 \pm 12.5$ & 0.06 & $61.6 \pm 11.7$ & $61.6 \pm 11.6$ & 0.00 \\
\hline Hypertension & $69.9 \%$ & $68.5 \%$ & -0.03 & $58.2 \%$ & $59.5 \%$ & 0.03 \\
\hline Diabetes & $30.6 \%$ & $29.1 \%$ & -0.03 & $17.3 \%$ & $18.2 \%$ & 0.02 \\
\hline Hypercholesterolaemia & $37.1 \%$ & $38.3 \%$ & 0.03 & $37 \%$ & $37.4 \%$ & 0.01 \\
\hline Current smoking & $30 \%$ & $29.7 \%$ & -0.01 & $64.8 \%$ & $64.9 \%$ & 0.00 \\
\hline Obesity & $24.9 \%$ & $23.7 \%$ & -0.03 & $14.2 \%$ & $15.1 \%$ & 0.03 \\
\hline Prior MI & $7.7 \%$ & $7.9 \%$ & 0.01 & $9.8 \%$ & $9.4 \%$ & -0.01 \\
\hline Prior $\mathrm{PCl}$ & $1.3 \%$ & $1.6 \%$ & 0.03 & $2.6 \%$ & $2.4 \%$ & -0.01 \\
\hline Prior $\mathrm{CABG}$ & $1.2 \%$ & $1 \%$ & -0.02 & $1.6 \%$ & $1.6 \%$ & 0.00 \\
\hline \multicolumn{7}{|l|}{ Systolic BP on admission: } \\
\hline$<100 \mathrm{~mm} \mathrm{Hg}$ & $9.5 \%$ & $10.3 \%$ & 0.03 & $7.8 \%$ & $8 \%$ & 0.01 \\
\hline $100-160 \mathrm{~mm} \mathrm{Hg}$ & $68.1 \%$ & $68.6 \%$ & 0.01 & $73.5 \%$ & $71.9 \%$ & -0.04 \\
\hline$>160 \mathrm{~mm} \mathrm{Hg}$ & $22.4 \%$ & $21.1 \%$ & -0.03 & $18.7 \%$ & $20.1 \%$ & 0.04 \\
\hline \multicolumn{7}{|l|}{ ECG on admission (rhythm): } \\
\hline Sinus rhythm & $91.3 \%$ & $89.9 \%$ & -0.05 & $93.4 \%$ & $92.9 \%$ & -0.02 \\
\hline Atrial fibrillation & $6.8 \%$ & $7.1 \%$ & 0.01 & $4.1 \%$ & $4.6 \%$ & 0.03 \\
\hline Pacing & $0.1 \%$ & $0.3 \%$ & 0.05 & $0.2 \%$ & $0.2 \%$ & 0.00 \\
\hline Other & $1.8 \%$ & $2.2 \%$ & 0.03 & $2.3 \%$ & $2.3 \%$ & 0.00 \\
\hline$H R>100 / \mathrm{min}$ & $9.5 \%$ & $10.3 \%$ & 0.03 & $7.4 \%$ & $8 \%$ & 0.02 \\
\hline \multicolumn{7}{|c|}{ ECG on admission (intraventricular conduction): } \\
\hline Normal & $86.7 \%$ & $85.9 \%$ & -0.02 & $87 \%$ & $86.5 \%$ & -0.02 \\
\hline LBBB & $2.2 \%$ & $2.8 \%$ & 0.04 & $1.9 \%$ & $1.8 \%$ & -0.01 \\
\hline RBBB & $2.7 \%$ & $2.9 \%$ & 0.01 & $3.3 \%$ & $3.4 \%$ & 0.01 \\
\hline Other & $8.4 \%$ & $8.4 \%$ & 0.00 & $7.7 \%$ & $8.3 \%$ & 0.02 \\
\hline \multicolumn{7}{|l|}{ Infarct location: } \\
\hline Anterior & $42 \%$ & $42.4 \%$ & 0.01 & $39.8 \%$ & $39.5 \%$ & -0.01 \\
\hline Inferior & $46.8 \%$ & $47.6 \%$ & 0.02 & $51.2 \%$ & $50.3 \%$ & -0.02 \\
\hline Other & $11.1 \%$ & $10 \%$ & -0.04 & $9 \%$ & $10.2 \%$ & 0.04 \\
\hline \multicolumn{7}{|c|}{ Time from symptom-onset to admission: } \\
\hline $0-2 \mathrm{~h}$ & $25.9 \%$ & $25.3 \%$ & -0.01 & $28.6 \%$ & $28.9 \%$ & 0.01 \\
\hline $2-12 \mathrm{~h}$ & $52 \%$ & $52.3 \%$ & 0.01 & $51.8 \%$ & $51.5 \%$ & -0.01 \\
\hline$>12 \mathrm{~h}$ & $22.2 \%$ & $22.4 \%$ & 0.01 & $19.6 \%$ & $19.7 \%$ & 0.00 \\
\hline Prehospital cardiac arrest & $1.9 \%$ & $2.3 \%$ & 0.03 & $3 \%$ & $2.5 \%$ & -0.03 \\
\hline \multicolumn{7}{|l|}{ Killip class on admission: } \\
\hline IV & $6.3 \%$ & $6.2 \%$ & 0.00 & $5.5 \%$ & $5.7 \%$ & 0.01 \\
\hline III & $3.2 \%$ & $3.6 \%$ & 0.02 & $2 \%$ & $2.1 \%$ & 0.01 \\
\hline II & $17.6 \%$ & $16.2 \%$ & -0.04 & $12.7 \%$ & $13.1 \%$ & 0.01 \\
\hline 1 & $72.9 \%$ & $74 \%$ & 0.03 & $79.8 \%$ & $79.1 \%$ & -0.02 \\
\hline \multicolumn{7}{|c|}{ Left ventricular ejection fraction: } \\
\hline$>50 \%$ & $48.2 \%$ & $45.3 \%$ & -0.06 & $48.7 \%$ & $47.6 \%$ & -0.02 \\
\hline $30-50 \%$ & $46.7 \%$ & $48.6 \%$ & 0.04 & $45.7 \%$ & $47.4 \%$ & 0.03 \\
\hline$<30 \%$ & $5.1 \%$ & $6.1 \%$ & 0.04 & $5.6 \%$ & $4.9 \%$ & -0.03 \\
\hline
\end{tabular}

S. diff. - standardised difference, $M I-$ myocardial infarction, $P C l$ - percutaneous coronary intervention, $C A B G$ - coronary artery bypass grafting, $B P$ - blood pressure, $H R$ - heart rate, $L B B B$ - left bundle branch block, $R B B B$ - right bundle branch block. 
7900 women (3950 from 2005 and 3950 from 2011) were matched. Standardised differences were calculated for assessing balance in baseline characteristics between subjects from 2005 and 2011 after propensity score matching (Table I). Relative in-hospital and 12-month mortality risk reductions were calculated for unmatched populations and were compared with the outcomes in the groups matched on the PS. The death rates in PS-matched groups represented the rates that would have been expected if the distribution of the baseline characteristics in 2005 and 2011 had been similar, therefore allowing us to estimate the excess of mortality reduction unrelated to patients' baseline profiles.

\section{Statistical analysis}

Categorical variables are presented as percentages. Significances of the differences between the study groups were assessed by the $\chi^{2}$ test. The cumulative probabilities of death during the 12 months after STEMI were calculated using the Kaplan-Meier method, and differences between groups were compared using the log-rank test. A two-sided $p$-value $\leq 0.05$ was considered significant. Calculations and statistical analyses were performed with Statistica 10 (StatSoft Inc., Tulsa, OK, USA), MedCalc (MedCalc Software, Belgium), and SPSS 17.0 (SPSS Inc., Chicago, IL, USA).

\section{Results}

In-hospital STEMI patient management underwent major changes between 2005 and 2011 in Poland (Table II). The use of coronary angiography and $\mathrm{PCl}$ were significantly more common in 2011 in both sexes, and only a small proportion of patients were treated conservatively or with thrombolysis. Emergent CABG (coronary artery bypass grafting) was performed in less than $0.1 \%$ of cases.

Changes in pharmacotherapy included more frequent use of potent antiplatelet agents and other evidence-based medications, especially when comparing drugs recommended at discharge (Tables III and IV).
In-hospital and 12-month crude mortality rates declined over the study period. The highest relative risk reductions (RRR) were observed for in-hospital mortality. RRR were higher in women than in men, especially in 12-month follow-up. Among patients hospitalised in 2011, absolute risk reduction of in-hospital death was $4.6 \%$ in women and $2.5 \%$ in men when compare to patients from 2005. This corresponds to $37 \%$ and $35 \%$ of RRR, respectively. After propensity score matching, RRR of in-hospital death was estimated at $21 \%$ for women and $27 \%$ for men, and for 12 -month mortality at $10 \%$ for women and $11 \%$ for men (Table V). The KaplanMeier curves showing the cumulative probabilities of death during the 12 months after STEMI among propensity score-matched subgroups from 2005 and 2011 are shown in Figure 1 (women) and Figure 2 (men). Advances in treatment could explain $57 \%$ of the observed relative risk reduction of in-hospital death in women and as much as $77 \%$ in men. For mortality at 12 months they accounted for $69 \%$ in men and $43 \%$ in women, of total observed mortality decline. However, for patients who survived the in-hospital period there was no further relative survival benefit that could be attributed to changes in management during the 12-month observation (Figure 3).

\section{Discussion}

\section{In-hospital mortality}

The highest relative risk reductions were observed for the in-hospital death rates. Crude inhospital mortality decreased from $7.1 \%$ to $4.6 \%$ in men and from $12.3 \%$ to $7.7 \%$ in women. There is a wide divergence in reported mortality rates across different regions and counties. The in-hospital mortality rates of unselected patients with STEMI in recently published data from national European registries vary between $4 \%$ and $12 \%$ [8]. Many studies present similar results to ours regarding changes of mortality rates over time. In Switzerland, between 1997 and 2011, in-hospital mortality decreased from $10 \%$ to $5 \%$ in men and from $18 \%$ to $7 \%$ in women [2]. When patients are mostly treated with $\mathrm{PCl}$, in-hospital mortality usually does

Table II. In-hospital management of ST-segment elevation patients admitted in 2005 and 2011 matched on the propensity scores

\begin{tabular}{|lcccccc|}
\hline In-hospital management & \multicolumn{3}{c}{ Women } & \multicolumn{3}{c|}{ Men } \\
\cline { 2 - 7 } & $\begin{array}{c}2005 \\
n=3950\end{array}$ & $\begin{array}{c}2011 \\
n=3950\end{array}$ & $P$-value & $\begin{array}{c}2005 \\
n=7080\end{array}$ & $\begin{array}{c}2011 \\
n=7080\end{array}$ & $P$-value \\
\hline Conservative treatment & $45.7 \%$ & $8.1 \%$ & $<0.01$ & $37 \%$ & $5.1 \%$ & $<0.01$ \\
\hline Thrombolysis & $8.6 \%$ & $0.6 \%$ & $<0.01$ & $8.5 \%$ & $0.3 \%$ & $<0.01$ \\
\hline Invasive treatment $-\mathrm{PCl}$ & $49.8 \%$ & $91.3 \%$ & $<0.01$ & $58.8 \%$ & $94.4 \%$ & $<0.01$ \\
\hline
\end{tabular}

$\mathrm{PCl}$ - percutaneous coronary intervention. 
Table III. In-hospital pharmacotherapy in ST-segment elevation patients admitted in 2005 and 2011 matched on the propensity scores

\begin{tabular}{|lcccccc|}
\hline In-hospital pharmacotherapy & \multicolumn{3}{c}{ Women } & \multicolumn{3}{c|}{ Men } \\
\cline { 2 - 7 } & $\begin{array}{c}2005 \\
n=3950\end{array}$ & $\begin{array}{c}2011 \\
n=3950\end{array}$ & $P$-value & $\begin{array}{c}2005 \\
n=7080\end{array}$ & $\begin{array}{c}2011 \\
n=7080\end{array}$ & $P$-value \\
\hline Acetylsalicylic acid & $93.8 \%$ & $88.9 \%$ & $<0.01$ & $94.8 \%$ & $90 \%$ & $<0.01$ \\
\hline Any thienopyridine & $62.5 \%$ & $98.1 \%$ & $<0.01$ & $70.8 \%$ & $98.4 \%$ & $<0.01$ \\
\hline Clopidogrel & $49.2 \%$ & $97.9 \%$ & $<0.01$ & $57 \%$ & $98.3 \%$ & $<0.01$ \\
\hline GP IIb/IIla blocker & $12.4 \%$ & $28.1 \%$ & $<0.01$ & $17.3 \%$ & $33.7 \%$ & $<0.01$ \\
\hline$\beta$-Adrenolytic & $70.2 \%$ & $68.5 \%$ & 0.1 & $72.6 \%$ & $73.6 \%$ & 0.2 \\
\hline Statin & $71 \%$ & $73.4 \%$ & 0.02 & $76 \%$ & $78.7 \%$ & 0.01 \\
\hline ACE inhibitor or ARB & $67.8 \%$ & $62.9 \%$ & $<0.01$ & $68.7 \%$ & $67.7 \%$ & 0.22 \\
\hline Calcium channel blocker & $4.4 \%$ & $8.3 \%$ & $<0.01$ & $3.2 \%$ & $6.9 \%$ & $<0.01$ \\
\hline Nitrate & $44.3 \%$ & $14.3 \%$ & $<0.01$ & $40.3 \%$ & $12.7 \%$ & $<0.01$ \\
\hline Diuretic & $30.2 \%$ & $23.2 \%$ & $<0.01$ & $21.2 \%$ & $16.8 \%$ & $<0.01$ \\
\hline
\end{tabular}

$G P$ - glycoprotein, ACE - angiotensin converting enzyme, ARB - angiotensin receptor blocker.

Table IV. Pharmacotherapy at discharge in ST-segment elevation patients admitted in 2005 and 2011 matched on the propensity scores

\begin{tabular}{|c|c|c|c|c|c|c|}
\hline \multirow[t]{2}{*}{ Pharmacotherapy at discharge } & \multicolumn{3}{|c|}{ Women } & \multicolumn{3}{|c|}{ Men } \\
\hline & $\begin{array}{c}2005 \\
n=3523\end{array}$ & $\begin{array}{c}2011 \\
n=3614\end{array}$ & $P$-value & $\begin{array}{c}2005 \\
n=6634\end{array}$ & $\begin{array}{c}2011 \\
n=6754\end{array}$ & $P$-value \\
\hline Acetylsalicylic acid & $83 \%$ & $93.6 \%$ & $<0.01$ & $84.1 \%$ & $94.2 \%$ & $<0.01$ \\
\hline Any thienopyridine & $58.1 \%$ & $90.6 \%$ & $<0.01$ & $65.9 \%$ & $91.3 \%$ & $<0.01$ \\
\hline Clopidogrel & $25.1 \%$ & $89.7 \%$ & $<0.01$ & $29.2 \%$ & $90.6 \%$ & $<0.01$ \\
\hline$\beta$-Adrenolytic & $73.5 \%$ & $85.4 \%$ & $<0.01$ & $75.0 \%$ & $85.3 \%$ & $<0.01$ \\
\hline Statin & $79.5 \%$ & $90.5 \%$ & $<0.01$ & $81.4 \%$ & $90.3 \%$ & $<0.01$ \\
\hline ACE inhibitor or ARB & $70.4 \%$ & $79.8 \%$ & $<0.01$ & $70.6 \%$ & $81.4 \%$ & $<0.01$ \\
\hline Calcium channel blocker & $4.6 \%$ & $8.5 \%$ & $<0.01$ & $3.4 \%$ & $7.5 \%$ & $<0.01$ \\
\hline Nitrate & $31.4 \%$ & $11.7 \%$ & $<0.01$ & $27.3 \%$ & $10.8 \%$ & $<0.01$ \\
\hline Diuretic & $25.2 \%$ & $26.9 \%$ & 0.1 & $17.4 \%$ & $18.5 \%$ & 0.09 \\
\hline
\end{tabular}

$A C E$ - angiotensin converting enzyme, $A R B$ - angiotensin receptor blocker.

Table V. Mortality of ST-segment elevation patients admitted in 2005 and 2011 - relative risk reductions in crude observed mortality rates and in mortality rates in patients matched on the propensity scores

\begin{tabular}{|c|c|c|c|c|c|c|c|c|c|}
\hline \multirow[t]{2}{*}{ Mortality rates } & \multicolumn{3}{|c|}{ In-hospital } & \multicolumn{3}{|c|}{ 12-month } & \multicolumn{3}{|c|}{ 12-month if discharged } \\
\hline & 2005 & 2011 & RRR & 2005 & 2011 & RRR & 2005 & 2011 & RRR \\
\hline \multicolumn{10}{|l|}{ Women: } \\
\hline Observed & $12.3 \%$ & $7.7 \%$ & $37 \%$ & $23.1 \%$ & $17.7 \%$ & $23 \%$ & $12.3 \%$ & $10.8 \%$ & $12 \%$ \\
\hline After PSM & $10.8 \%$ & $8.5 \%$ & $21 \%$ & $20.9 \%$ & $18.8 \%$ & $10 \%$ & $11.3 \%$ & $11.3 \%$ & $0 \%$ \\
\hline \multicolumn{10}{|l|}{ Men: } \\
\hline Observed & $7.1 \%$ & $4.6 \%$ & $35 \%$ & $15.1 \%$ & $12.7 \%$ & $16 \%$ & $8.6 \%$ & $8.4 \%$ & $2 \%$ \\
\hline After PSM & $6.3 \%$ & $4.6 \%$ & $27 \%$ & $13.8 \%$ & $12.2 \%$ & $11 \%$ & $8.0 \%$ & $8.0 \%$ & $0 \%$ \\
\hline
\end{tabular}

$P S M$ - propensity score matching, $R R R$ - relative risk reduction. 
not exceed $6-7 \%[3,17]$ and could be as low as $3.59 \%$, as reported in men in a single-state American study [17]. However, some real-life data from Germany have shown surprisingly high in-hospital mortality rates and even a slight increase in STEMI in-hospital mortality from $11.2 \%$ in 2005 to $12.2 \%$ in 2009 [18]. Some sex-related disparities were also reported $[1,19]$. In an Italian study, in-hospital mortality presented a small decrease from $7.6 \%$ in 2000 to $6.2 \%$ in 2010 in men, whereas it remained higher and substantially constant over time in women (16.6\% in 2000, $15.5 \%$ in 2010) [1].

Most authors assume that new treatments should be the main reason for mortality reduction. Our study confirms that the progress in treatment contributed towards substantial reduction of mortality, and it could explain most of the in-hospital mortality decrease, especially in men. Two large American studies based on data from the NRMI (National Registry of Myocardial Infarction) estimated that in 1990-2006 relative reduction of hospital death in patients with STEMI after adjustment for baseline covariates was 24.2\% [20]. Improved adherence to guideline therapies including the use of timely reperfusion accounted for $21 \%$ of the annual decline in the risk for hospital mortality among this population [7]. In our study the relative reduction in hospital mortality attributable to temporal improvements in hospital management has been estimated at similar levels: $27 \%$ for men and $21 \%$ for women, despite different region and time points for data collection. The sex-related difference is our specific finding. In men it constituted $77 \%$ of total observed RRR, whereas in women this fraction was considerably smaller (57\%). Similarly, a French study estimated that a $74 \%$ reduction of absolute 30 -day mortality between 1995 and 2010 could be attributed to the advances in treatment [4], but no sex-specific results were presented.

It has been reported that in recent years women experienced greater improvements in hospital mortality after MI than did men. Changes in comorbidity and clinical severity features at admission accounted for more than $90 \%$ of these mortality trends [21]. Our study supports similar findings in the Polish population. Relatively more positive changes in the baseline risk status (which might partly also be a consequence of pre-hospital management) definitely helped women to achieve substantial mortality rate reductions, despite the fact that men seemed to benefit more from the improved in-hospital treatment strategies. It may suggest that some sex-related disparities in STEMI treatment could still be present and should be explored further.

Besides improved frequencies of $\mathrm{PCl}$ reperfusion there was also the increased use of in-hos-

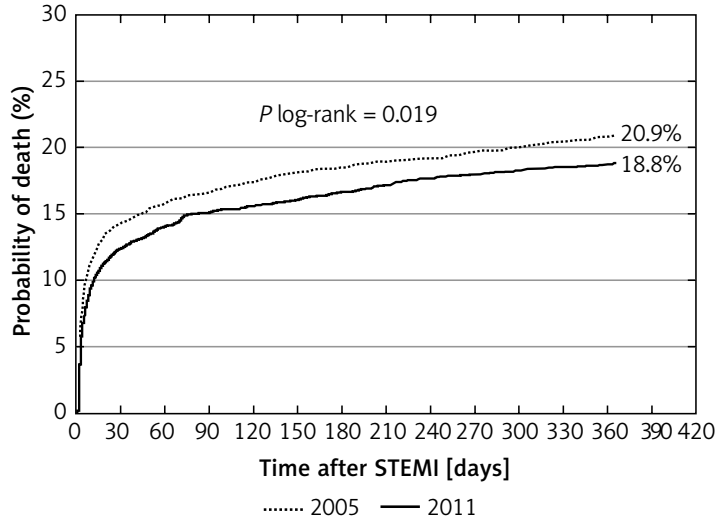

Figure 1. 12-month mortality after ST-segment elevation among propensity score-matched subgroups of women from 2005 and 2011

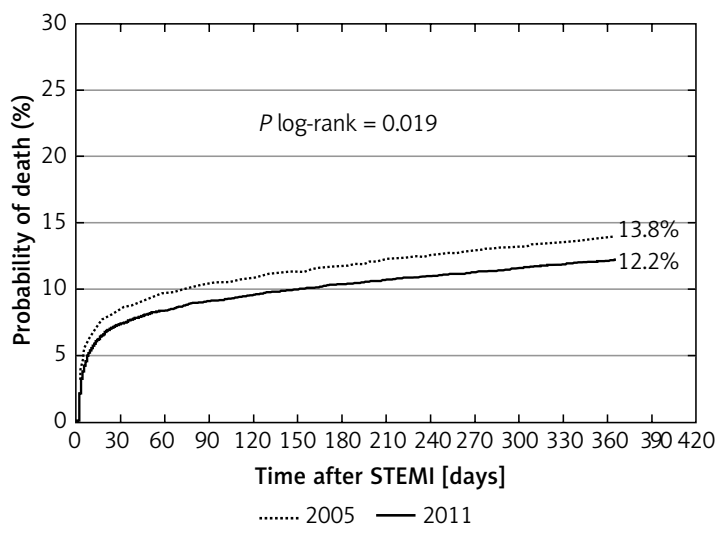

Figure 2. 12-month mortality after ST-segment elevation among propensity score-matched subgroups of men from 2005 and 2011

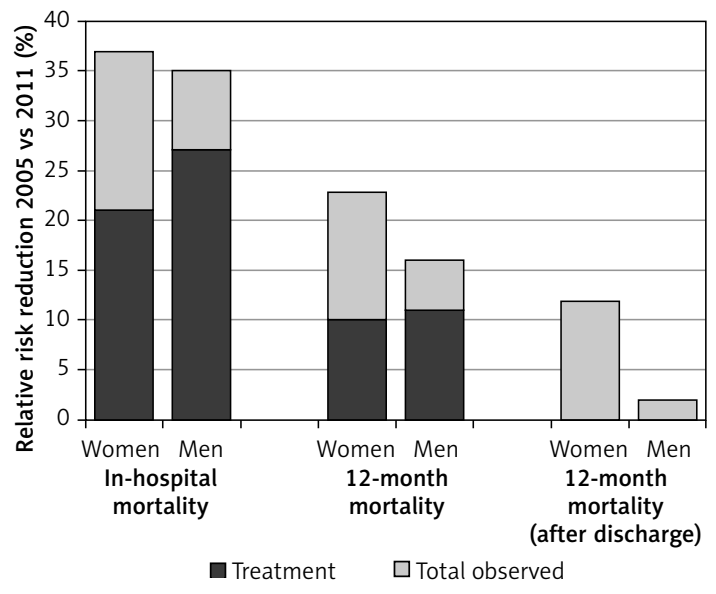

Figure 3. Fractions of total observed mortality decline that could be attributed to changes in treatment (adjusted for baseline characteristics at admission)

pital novel antiplatelet agents (thienopyridines/ clopidogrel and Ilb/IIla inhibitors). At the same time the use of aspirin decreased, which was clearly contrary to current guidelines. It might be explained by the increase in novel antiplatelet 
agents usage and physicians being less insistent on dual-antiplatelet therapy in patients with even a minor intolerance to aspirin or an increased risk of bleeding. Single authors reported similar tendencies in aspirin usage in secondary prevention [22]. We did not observe significant changes in the hospital use of $\beta$-blockers and only a small increase in the use of statins. The routine administration of nitrates or diuretics in STEMI was not shown to be of value [23]. Although the proportions of patients according to Killip Class at admission were balanced (Table I), the lower in-hospital use of diuretics and nitrates could still be associated with a lower proportion of patients with signs or symptoms of congestion or acute cardiac failure during subsequent days of hospitalisation. It might also suggest lower rates of recurrent ischaemic pain, which required the use of nitrates; this was also true for discharge medications. The significant decrease in the in-hospital use of angiotensin converting enzyme (ACE) inhibitors or angiotensin receptor blockers (ARB) in women was unexpected. Early ACE inhibition has been shown to reduce mortality as early as 30 days after STEMI, with most of the benefit observed in the first week [24]. The in-hospital use of ACE inhibitors or ARB remained relatively constant in men whereas it significantly decreased in women. It is not clear why this class of drugs was becoming less frequently used in women. AMIS-Plus (National Registry of Acute Myocardial Infarction in Switzerland) investigators from Switzerland also presented data that ACE inhibitors/ARB were less frequently used in women [2] despite the fact that earlier data from the same registry showed no differences in this field [25]. This finding could contribute towards the relatively small (compared to men) portion of the total observed in-hospital mortality decrease among women attributable to changes in hospital treatment.

\section{2-month mortality}

Data on sex-specific identification of reasons for longer term mortality decrease in STEMI are lacking. In our study, RRRs of crude 12-month mortality rates were considerably smaller when compare to RRRs of in-hospital mortality. They were also higher in women, but the changes in management had similar overall benefit to both sexes with $10-11 \%$ of RRRs being independent of patients' clinical profiles. It suggests that women experienced greater overall 12-month mortality RRR, when compared to men, mostly due to changes in their initial risk-profiles. Relatively more positive changes in female patients' characteristics at admission may epitomise the closing of the sex-gap reported in many previous studies $[2,7,19,26]$.
The long-term effects of the hospital survival improvements were still noticeable after 12 months. However, no added benefit of changes in post-hospital management was detected (Figure 3); the 12-month mortality reduction observed in crude real-life data among patients discharged from hospitals could be fully explained by changes in their clinical profiles at admission.

It is well known that patients after STEMI have a higher risk of death after leaving the hospital than the representatives of the general population, and secondary prevention therapies have been shown to improve their survival [23]. We observed an optimistic change in the guideline-recommended pharmacotherapy at discharge, with around a $10 \%$ absolute increase in the prescription of beta blockers, ACE inhibitors/ARB, and statins in both sexes. However, it did not help enough to detect any treatment-related advantage in 12-month mortality at the population level among the patients discharged from the hospital. There might be unsatisfactory patient adherence to discharge recommendations, subsequent suboptimal modification of the pharmacotherapy, lack of proper lifestyle modifications, or other non-pharmacological interventions. There has been a report from a Polish population on secondary prevention therapies in coronary artery disease, including 2005-2006 and 2011-2013 time periods, suggesting room for further improvement in the prescription of guideline-recommended drugs, especially when post-hospital care is provided by primary care physicians [27]. There is also a potential concern that some patients survived the in-hospital period owing to improved treatment, but they remained at increased risk of death in the following months despite changes in the post-discharge care. These issues need to be explored further to possibly improve longer-term outcomes in STEMI patients.

A number of possible limitations of our study should be mentioned. First is the retrospective nature of the registry data. We believe that the propensity score matching technique is currently the most appropriate approach to eliminate the effects of confounding when using observational data and identifying causal relationships from a large non-randomised data set. However, some initial patients' characteristics were not available (for example data on renal failure or anaemia), which might have affected the PS model quality. Participation in the PL-ACS Registry is voluntary, and the participating sites varied during the study period, so selection bias cannot be excluded. Finally, it is a single-country study, and generalising our findings on other populations with differing regions and time points for the data collection is tentative. Despite the listed limitations, we believe that our study allows a good view on recent 
changes in STEMI management in a real-life setting and their actual relation to survival improvement, and it highlights the areas that require additional research and clinical attention.

In conclusion, there were substantial changes in STEMI patient management between 2005 and 2011 in Poland. Most of them followed current guideline recommendations and helped to achieve better survival rates in STEMI patients. Higher mortality risk reductions were observed in women, and they were driven by more positive changes in the females' baseline risk profiles when compared to men. In contrast, men seemed to benefit relatively more from improvements in hospital treatment. Relative 12-month mortality reduction rates were less pronounced and could be fully explained by changes in patients' initial characteristics and in-hospital mortality decline. The clinicians should pay attention to in-hospital use of aspirin in both sexes and ACE inhibitors/ $A R B$ in women and also focus on post-discharge management to possibly prolong the positive aspects of in-hospital efforts.

\section{Conflict of interest}

The authors declare no conflict of interest.

\section{References}

1. Corrada E, Ferrante G, Mazzali C, et al. Eleven-year trends in gender differences of treatments and mortality in ST-elevation acute myocardial infarction in northern Italy, 2000 to 2010. Am J Cardiol 2014; 114: 336-41.

2. Radovanovic D, Nallamothu BK, Seifert B, et al. Temporal trends in treatment of ST-elevation myocardial infarction among men and women in Switzerland between 1997 and 2011. Eur Heart J Acute Cardiovasc Care 2012; 1: 183-91.

3. Tousek P, Tousek F, Horak D, et al. The incidence and outcomes of acute coronary syndromes in a central European country: results of the CZECH-2 registry. Int I Cardiol 2014; 173: 204-8.

4. Puymirat E, Simon T, Steg PG, et al. Association of changes in clinical characteristics and management with improvement in survival among patients with ST-elevation myocardial infarction. JAMA 2012; 308: 998-1006.

5. Zandecki L, Sadowski M, Janion M, Gierlotka M, Gasior M, Polonski L. Trends in sex differences in clinical characteristics, treatment strategies, and mortality in patients with ST-elevation myocardial infarction in Poland from 2005 to 2011. Coron Artery Dis 2017; 28: 417-25.

6. Smolina K, Wright FL, Rayner M, Goldacre MJ. Determinants of the decline in mortality from acute myocardial infarction in England between 2002 and 2010: linked national database study. BMJ 2012; 344: d8059.

7. Peterson ED, Shah BR, Parsons L, et al. Trends in quality of care for patients with acute myocardial infarction in the National Registry of Myocardial Infarction from 1990 to 2006. Am Heart J 2008; 156: 1045-55.

8. Ibanez B, James S, Agewall S, et al. 2017 ESC Guidelines for the management of acute myocardial infarc- tion in patients presenting with ST-segment elevation: The Task Force for the management of acute myocardial infarction in patients presenting with ST-segment elevation of the European Society of Cardiology (ESC). Eur Heart J 2018; 39: 119-77.

9. Hong MK. Recent advances in the treatment of ST-segment elevation myocardial infarction. Scientifica 2012; 2012: 683683.

10. Kristensen SD, Laut KG, Fajadet J, et al. Reperfusion therapy for ST elevation acute myocardial infarction 2010/2011: current status in 37 ESC countries. Eur Heart J 2014; 35: 1957-70.

11. Dudek D, Legutko J, Siudak Z, et al. Interventional cardiology in Poland in the year 2011. Summary report of the Association of Cardiovascular Interventions of the Polish Cardiac Society. Adv Interv Cardiol 2012; 8: 102-7.

12. Gierlotka M, Zdrojewski T, Wojtyniak B, et al. Incidence, treatment, in-hospital mortality and one-year outcomes of acute myocardial infarction in Poland in 2009-2012 - nationwide AMI-PL database. Kardiol Pol 2015; 73 : 142-58.

13. Jernberg T, Johanson P, Held C, et al. Association between adoption of evidence-based treatment and survival for patients with ST-elevation myocardial infarction. JAMA 2011; 305: 1677-84.

14. Trzeciak P, Gierlotka M, Gąsior M, et al. Mortality of patients with ST-segment elevation myocardial infarction and cardiogenic shock treated by $\mathrm{PCl}$ is correlated to the infarct-related artery: results from the PL-ACS Registry. Int J Cardiol 2013; 166: 193-7.

15. Rosenbaum PR, Rubin DB. The central role of the propensity score in observational studies for causal effects. Biometrika 1983; 70: 41-55.

16. Austin PC. Primer on statistical interpretation or methods report card on propensity-score matching in the cardiology literature from 2004 to 2006: a systematic review. Circ Cardiovasc Qual Outcomes 2008; 1: 62-7.

17. Jackson EA, Moscucci $M$, Smith DE, et al. The association of sex with outcomes among patients undergoing primary percutaneous coronary intervention for ST elevation myocardial infarction in the contemporary era: Insights from the Blue Cross Blue Shield of Michigan Cardiovascular Consortium (BMC2). Am Heart J 2011; 161: 106-112.e1.

18. Freisinger E, Fuerstenberg T, Malyar NM, et al. German nationwide data on current trends and management of acute myocardial infarction: discrepancies between trials and real-life. Eur Heart J 2014; 35: 979-88.

19. Sadowski M, Gasior M, Gierlotka M, Janion M, Poloński L. Gender-related differences in mortality after ST-segment elevation myocardial infarction: a large multicentre national registry. EuroIntervention 2011; 6: 1068-72.

20. Rogers WJ, Frederick PD, Stoehr E, et al. Trends in presenting characteristics and hospital mortality among patients with ST elevation and non-ST elevation myocardial infarction in the National Registry of Myocardial Infarction from 1990 to 2006. Am Heart J 2008; 156: 1026-34.

21. Vaccarino V, Parsons L, Peterson ED, Rogers WJ, Kiefe Cl, Canto J. Sex differences in mortality after acute myocardial infarction: changes from 1994 to 2006. Arch Intern Med 2009; 169: 1767-74.

22. Gale CP, Allan V, Cattle BA, et al. Trends in hospital treatments, including revascularisation, following acute myocardial infarction, 2003-2010: a multilevel and relative survival analysis for the National Institute for Car- 
diovascular Outcomes Research (NICOR). Heart Br Card Soc 2014; 100: 582-9.

23. Task Force on the management of ST-segment elevation acute myocardial infarction of the European Society of Cardiology (ESC), Steg PG, James SK, Atar D, et al. ESC guidelines for the management of acute myocardial infarction in patients presenting with ST-segment elevation. Eur Heart J 2012; 33: 2569-619.

24. ISIS-4: a randomised factorial trial assessing early oral captopril, oral mononitrate, and intravenous magnesium sulphate in 58,050 patients with suspected acute myocardial infarction. ISIS-4 (Fourth International Study of Infarct Survival) Collaborative Group. Lancet Lond Engl 1995; 345: 669-85.

25. Radovanovic D, Erne P, Urban P, et al. Gender differences in management and outcomes in patients with acute coronary syndromes: results on 20,290 patients from the AMIS Plus Registry. Heart Br Card Soc 2007; 93: 1369-75.

26. Sadowski M, Gutkowski W, Raczyński G, Janion-Sadowska A, Gierlotka M, Poloński L. Acute myocardial infarction due to left main coronary artery disease in men and women: does ST-segment elevation matter? Arch Med Sci 2015; 11: 1197-204.

27. Jankowski P, Czarnecka D, Badacz L, et al. Practice setting and secondary prevention of coronary artery disease. Arch Med Sci 2018; 14: 979-87. 